Pathophysiology

of Haemostasis and Thrombosis
Pathophysiol Haemost Thromb 2005;34:284-287

DOI: $\underline{10.1159 / 000093109}$
Received: April 15, 2005

Accepted after revision: September 27, 2005

\title{
Evolution of Thrombin Formation and Fibrinolysis Markers, Including Thrombin- Activatable Fibrinolysis Inhibitor, during Severe Meningococcemia
}

\author{
Marc Fouassier $^{a}$ Delphine Moreau $^{b}$ Fabrice Thiollière $^{b}$ Corinne Frère $^{c}$ \\ Alain Marquès-Verdier ${ }^{a}$ Bertrand Souweine $^{b}$



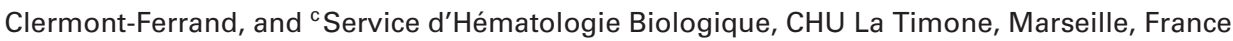

\section{Key Words}

Meningococcemia - Coagulation · Fibrinolysis ·

Thrombin-activatable fibrinolysis inhibitor $\cdot$ Protein $\mathrm{C}$ concentrates

\begin{abstract}
A 17-year-old girl presented with Neisseria meningitidis sepsis, with evidence of disseminated intravascular coagulation. Substitution therapy with both antithrombin and protein $\mathrm{C}$ concentrates was initiated, leading to clinical and biological improvement. Sequential dosages were performed for biological markers including thrombin-activatable fibrinolysis inhibitor (TAFI). Substitution therapy with both antithrombin and protein $\mathrm{C}$ concentrates led to a clinical and biological improvement. Biological markers showed a decrease in thrombin generation and in plasminogen activator inhibitor 1 (PAl-1) and a return of TAFI to a normal value. Discontinuation of substitutive treatment was marked by a clinical relapse at $24 \mathrm{~h}$, with thrombin generation and increase in PAI-1, while TAFI remained unchanged. This report shows the evolution of hemostasis markers during septic shock and provides new data concerning the effects of a substitutive therapy.
\end{abstract}

\section{KARGER}

Fax +4161306 1234 E-Mail karger@karger.ch www.karger.com
Purpura fulminans when encountered with bloodstream invasion by Neisseria meningitidis is a devastating disease and has a mortality rate in excess of 50\%. Disseminated intravascular coagulation (DIC) is observed in severe infections with impairment of both the anticoagulant pathways and the fibrinolysis system. Low plasma protein $\mathrm{C}(\mathrm{PC})$ is associated with poor prognosis [1]. In a recent study (PROWESS study), the administration of recombinant human activated $\mathrm{PC}$, which bypasses the activation step of $\mathrm{PC}$ (the activation of $\mathrm{PC}$ is often diminished in sepsis because of poor reserve of thrombomodulin in microcirculation), in patients with septic shock significantly reduced mortality, but led to an increased risk of bleeding [2]. There is no reported evidence that recombinant human activated PC is more effective than PC concentrates in purpura fulminans while experimental and clinical findings suggest that PC concentrates may be safer, concerning hemorrhagic complications, than human activated PC $[3,4]$. The aim of the study was to assess the impact of PC concentrate treatment on the dysregulation of coagulation and fibrinolysis in human subjects during sepsis. This report describes the evolution of different markers of coagulation and fibrinolysis, including the thrombin-activatable fibrinolysis inhibitor(TAFI), after antithrombin (AT) and PC concentrate infusions in a patient with purpura fulminans [5]. 


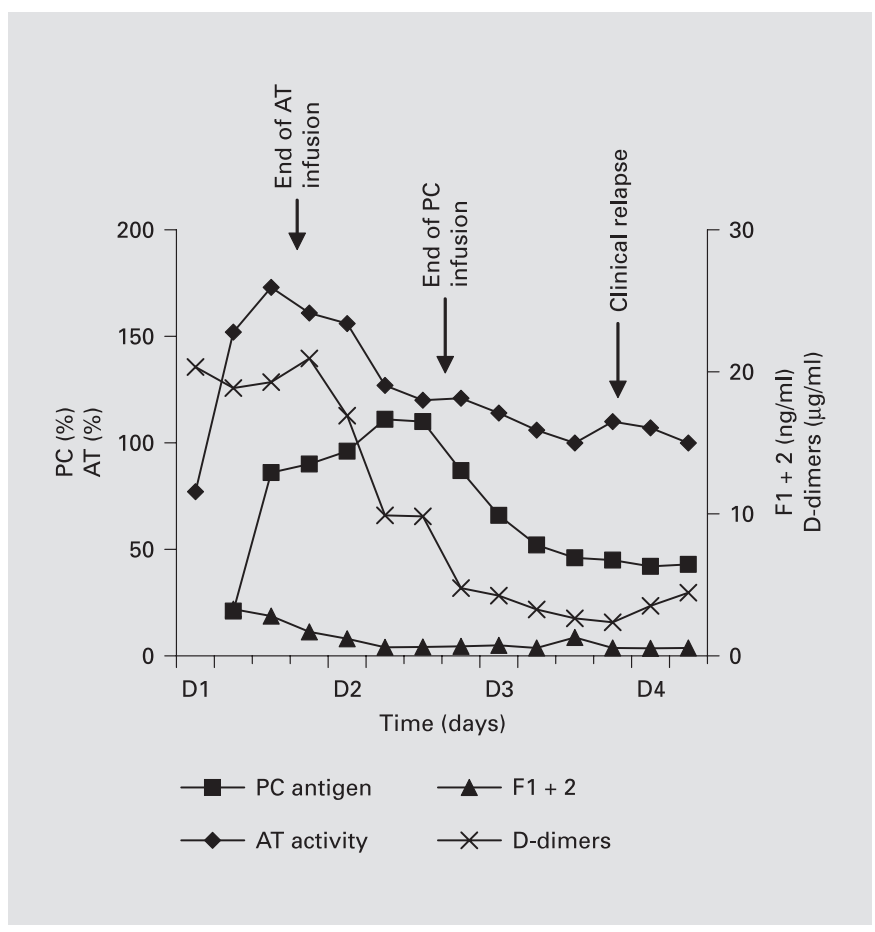

Fig. 1. Coagulation parameters during the first 6 days.

\section{Case Report}

A 17-year-old girl was admitted to the ICU with a 36-hour history of fever and headache and the recent onset of a petechial rash, acute confusion and meningism. She presented with hypotension (76/40 $\mathrm{mm} \mathrm{Hg}$ ), tachycardia (114 bpm), oliguria, widely scattered necrotic purpuric lesions and altered mental status (Glasgow coma score 14). There was clear evidence of DIC: platelet count $67 \mathrm{Giga} / 1$, prothrombin level $37 \%$ of normal range, factor $\mathrm{V} 40 \%$, and elevated D-dimers $(20 \mu \mathrm{g} / \mathrm{ml})$. The plasma PC value was low $(21 \%)$. The plasma fibrinogen level was normal as was the plasma AT level (77\%). Ceftriaxone treatment ( $2 \mathrm{~g} /$ day) was initiated in combination with appropriate supportive care (fluid expansion, mechanical ventilation, vasopressors). Blood culture subsequently yielded type $\mathrm{C} N$. meningitidis.

Substitution therapy was initiated $4 \mathrm{~h}$ after admission with both AT (Aclotine ${ }^{\circledR}$, LFB, France; $100 \mathrm{IU} / \mathrm{kg}$ bolus and $100 \mathrm{IU} / \mathrm{kg} /$ day) and PC concentrates (Protexel ${ }^{\circledR}$, LFB, France; $100 \mathrm{IU} / \mathrm{kg}$ bolus twice and $240 \mathrm{IU} / \mathrm{kg} /$ day). There was an improvement of the patient's general condition and of the coagulation parameters. AT and $\mathrm{PC}$ infusions were discontinued at $16 \mathrm{~h}(\mathrm{AT}=173 \%)$ and $36 \mathrm{~h}$ $(\mathrm{PC}=110 \%)$, respectively. Twenty-four hours later, her condition deteriorated rapidly with extensive new purpuric and necrotic lesions, and echocardiography confirmed cardiogenic shock (biventricular dysfunction). Histological examination of new skin lesions showed leukocytoclastic vasculitis.

The biopsy specimen from a purpuric lesion showed inflammatory cells around nonthrombosed vessels. The cellular infiltrate

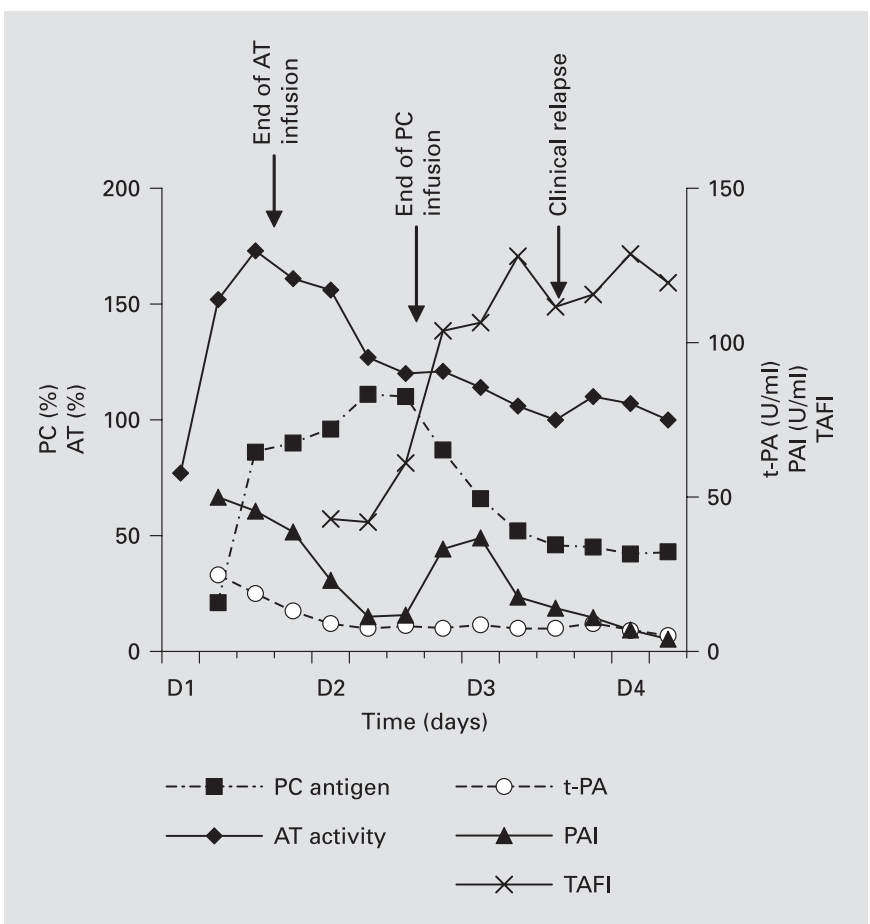

Fig. 2. Fibrinolysis parameters during the first 6 days.

consisted of both polymorphonuclear neutrophils and monocytes. The patient's clinical condition improved rapidly within $24 \mathrm{~h}$ with dobutamine and diuretics, and a second infusion of PC concentrates, which was considered, was finally cancelled. She was discharged from the hospital 7 days later with no sequel. An exhaustive exploration of her coagulation system performed 3 months later ruled out the possibility of an underlying constitutive coagulation disorder.

Results of sequential dosages given for the following biological markers (AT, PC and D-dimers were tested in fresh samples, other markers in thawed samples) are shown in figures 1 and 2: PC (VIDAS Protein C, bioMérieux, Lyon, France), AT (Berichrom AT III, Dade Behring, Marburg, Germany), prothrombin fragments 1 and 2 (F1 + 2; Enzygnost F $1+2$ micro, Dade Behring), D-dimers (VIDAS D-Dimer New, bioMérieux), t-PA and plasminogen activator inhibitor (PAI) antigens (Zymutest t-PA and Zymutest PAI, Hyphen Biomed, Andresy, France).

TAFI antigen levels were determined with a noncommercial ELISA assay based on the combination of two monoclonal antibodies. Calibration was performed with a pool of plasma from 30 healthy individuals and results were expressed as percentage versus normal plasma. This assay does not react toward the carboxypeptidase $\mathrm{N}$ which is constitutively active in plasma. All properties of this ELISA are described in a recent article [6]. 


\section{Discussion}

In this observation, we report the evolution of key markers of coagulation and fibrinolysis disorders (including TAFI) during both the improvement and the relapse of a disease that can be considered as a clinical model of septic DIC-related organ failure. During severe sepsis, there is an overwhelming release of proinflammatory compounds, which is insufficiently counterbalanced by the release of anti-inflammatory mediators. As a result there is thrombin generation and fibrin clot formation due to tissue factor expression, decreased PC activation, which results from thrombomodulin depletion and/or dysfunction of endothelial PC activation, and acute depletion in AT [7, 8] and, then, inhibition of fibrinolysis by generation of PAI- 1 and TAFI.

Although TAFI is now considered as a key molecule in the coagulation/fibrinolysis equilibrium $[9,10]$, very little is known about its involvement in severe human sepsis, and there are no data regarding its evolution in patients surviving DIC with multiple organ failure. In our patient, the initial level of TAFI was low presumably due to increased consumption by massive thrombin generation [11]. This finding is consistent with a previous report of TAFI in sepsis-related DIC [12]. Furthermore, a recent study highlights the possible involvement of the TAFI 325 Ile/Ile variant (which increases TAFIa stability and activity) in the susceptibility of patients for meningococcal disease and in the mortality related to this disease [13]. After initiation of replacement therapy, there was improvement of organ function and cutaneous vasculitis followed by a rapid decrease in thrombin generation as suggested by the decreases in F1 +2 . The decrease in throm- bin generation can be ascribed both to direct inhibition of factor Xa by the infused AT and to activation of the infused PC, which inactivates the extrinsic pathway through inhibition of factors Va and VIIIa. In parallel, we observed a decrease in PAI-1 and D-dimer levels and a rapid return of TAFI to a normal value on day 3 . The rise in TAFI levels during treatment was probably due to the decrease in fibrin generation.

The interruption of PC infusion was rapidly followed by manifestations attributable to the recurrence of a systemic vasculitis, in the form of necrotic skin lesions and acute organ dysfunction with cardiac failure. The vasculitis relapsed clinically while there was both recurrent thrombin generation, as demonstrated by the rise in $\mathrm{F} 1+2$, and a peak of antifibrinolytic activity as suggested by the increase in PAI-1. PAI-1 is currently considered as a key marker in the genesis of organ failure in sepsis. The stable level of D-dimers was not in favour of DIC.

This report highlights the difficulty of determining the optimal duration of PC infusions, which should be discontinued as early as possible because of the theoretical hemorrhagic risk, but maintained long enough to avoid reactivation of the vasculitis by favoring optimal coagulation/fibrinolysis balance throughout the procoagulant period.

This report also provides new data regarding the evolution of TAFI during the acute phase of septic shock and subsequent recovery. Further studies are needed to determine the optimal duration of substitutive treatments in such difficult cases of thrombotic DIC, and to assess the potential value of monitoring coagulation markers such as PAI-1 and TAFI.

\section{References}

1 White B, Livingstone W, Murphy C, Hodgson A, Rafferty M, Smith OP: An open-label study of the role of adjuvant hemostatic support with protein $\mathrm{C}$ replacement therapy in purpura fulminans-associated meningococcemia. Blood 2000;96:3719-3724.

-2 Bernard GR, Vincent JL, Laterre PF, LaRosa SP, Dhainaut JF, Lopez-Rodriguez A, Steingrub JS, Garber GE, Helterbrand JD, Ely EW, Fisher CJ Jr; Recombinant human protein C Worldwide Evaluation in Severe Sepsis (PROWESS) study group: Efficacy and safety of recombinant human activated protein $\mathrm{C}$ for severe sepsis. N Engl J Med 2001;344:699_ 709.

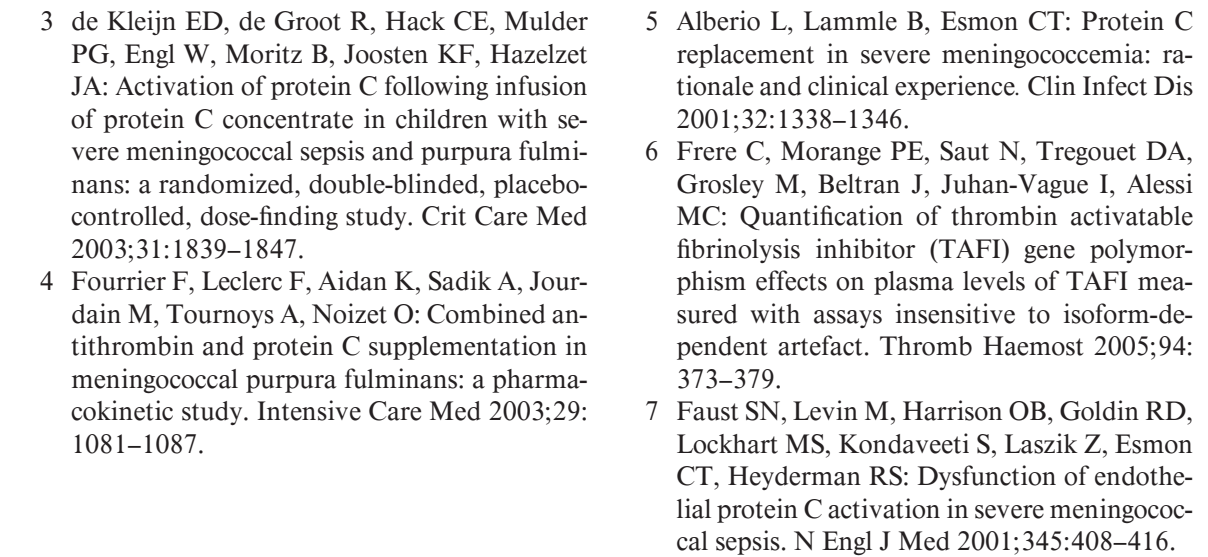

Fouassier/Moreau/Thiollière/Frère/ Marquès-Verdier/Souweine 
$>8$ Levi M, Ten Cate H: Disseminated intravascular coagulation. N Engl J Med 1999;341: 586-592.

$\checkmark 9$ Nesheim M, Wang W, Boffa M, Nagashima M, Morser J, Bajzar L: Thrombin, thrombomodulin and TAFI in the molecular link between coagulation and fibrinolysis. Thromb Haemost 1997;78:386-391.

10 Nesheim M: Thrombin and fibrinolysis. Chest 2003; 124:33S-39S
1 Meijers JC, Oudijk EJ, Mosnier LO, Bos R, Bouma BN, Nieuwenhuis HK, Fijnheer R: Reduced activity of TAFI (thrombin-activatable fibrinolysis inhibitor) in acute promyelocytic leukaemia. Br J Haematol 2000; 108:518523.

12 Watanabe R, Wada H, Watanabe Y, Sakakura M, Nakasaki T, Mori Y, Nishikawa M, Gabazza EC, Nobori T, Shiku H: Activity and antigen levels of thrombin-activatable fibrinolysis inhibitor in plasma of patients with disseminated intravascular coagulation. Thromb Res 2001; 104:1-6.
3 Kremer Honinga JA, Franco RF, Zago MA, Ten Cate H, Westendorp RGJ, Reitsma PH: A functional single nucleotide polymorphism in the thrombin-activatable fibrinolysis inhibitor (TAFI) gene associates with outcome of meningococcal disease. J Thromb Haemost 2004; 2: 54-57. 